\title{
DETERMINATION OF CONSTANT PARAMETERS OF COPPER AS POWER-LAW HARDENING MATERIAL AT DIFFERENT TEST CONDITIONS
}

\author{
Md. A. KOWSER ${ }^{*}$ and Md. MAHIUDDIN \\ Department of Mechanical Engineering \\ Dhaka University of Engineering and Technology (DUET) \\ Gazipur, BANGLADESH \\ E-mail: nadimduet@yahoo.com
}

\begin{abstract}
In this paper a technique has been developed to determine constant parameters of copper as a power-law hardening material by tensile test approach. A work-hardening process is used to describe the increase of the stress level necessary to continue plastic deformation. A computer program is used to show the variation of the stress-strain relation for different values of stress hardening exponent, $n$ and power-law hardening constant, $\alpha$. Due to its close tolerances, excellent corrosion resistance and high material strength, in this analysis copper $(\mathrm{Cu})$ has been selected as the material. As a power-law hardening material, $\mathrm{Cu}$ has been used to compute stress hardening exponent, $n$ and power-law hardening constant, $\alpha$ from tensile test experiment without heat treatment and after heat treatment. A wealth of information about mechanical behavior of a material can be determined by conducting a simple tensile test in which a cylindrical specimen of a uniform cross-section is pulled until it ruptures or fractures into separate pieces. The original cross sectional area and gauge length are measured prior to conducting the test and the applied load and gauge deformation are continuously measured throughout the test. Based on the initial geometry of the sample, the engineering stress-strain behavior (stress-strain curve) can be easily generated from which numerous mechanical properties, such as the yield strength and elastic modulus, can be determined. A universal testing machine is utilized to apply the load in a continuously increasing (ramp) manner according to ASTM specifications. Finally, theoretical results are compared with these obtained from experiments where the nature of curves is found similar to each other. It is observed that there is a significant change of the value of $n$ obtained with and without heat treatment it means the value of $n$ should be determined for the heat treated condition of copper material for their applications in engineering fields.
\end{abstract}

Key words: stress hardening exponent, power-law hardening constant, work-hardening process, power-law hardening material, heat treatment, tensile test, stress-strain curve.

\section{Introduction}

In elastic limit, strain is proportional to stress. So, within this limit, every level of stress causes some elastic deformation. On the other hand, a certain level of stress must be applied before plastic deformation starts. In the plastic deformation regime, the total strain is the sum of the elastic strain and the plastic strain. The contribution of elastic strain in total strain is much less than that of plastic strain. So, in plastic deformation range, the strain basically signifies plastic strain (Hosford, 2005; Rivello, 1960; Batdorf and Budiansky, 1949; Sanders, 1954; Perrone and Hodge, 1957).

The nonlinear elastic-plastic behavior is considered the same as that suggested by Ramberg and Osgood (1943) to model the tensile stress-strain relations

$$
\varepsilon=\sigma+\alpha \sigma^{n}
$$

\footnotetext{
* To whom correspondence should be addressed
} 
where $\sigma$ is the true stress, $\alpha$ is the power-law hardening constant, $\varepsilon$ is the true plastic strain and $\mathrm{n}$ is the stress hardening exponent. The early research work in this field can be found in Hutchinson (1967), Kucharski and Mróz (2007), Isakson et al. (1967), Xia and Tzuchiang (1994), Lin and Tzuchiang (1992), Denke (1956). Material parameters $\alpha$ and $n$ are identified by Kucharski and Mróz (2007) from spherical indentation tests.

Stress hardening is the strengthening of the metal by plastic deformation. This strengthening occurs because of dislocation movements within the crystal structure of the material (Xia and Wang, 1993; Prager, 1956; Symonds and Prager, 1950; Hodge, 1959; Ramberg and Osgood, 1943; Naghdi, 1960).

Before stress hardening, the lattice of the material exhibits a regular, nearly defect-free pattern (almost no dislocations). The defect-free lattice can be created or restored at any time by annealing. As the material is work hardened it becomes increasingly saturated with new dislocations, and more dislocations are prevented from nucleating (a resistance to dislocation-formation develops). This resistance to dislocationformation manifests itself as a resistance to plastic deformation; hence, the observed strengthening (Marin and Hue, 1953; Prager, 1955; Neal, 1950).

In metallic crystals, irreversible deformation is usually carried out on a microscopic scale by defects called dislocations, which are created by fluctuations in local stress fields within the material. This irreversible deformation gets culminated as the dislocation propagates through the lattice arrangement. At normal temperatures, the dislocations are not annihilated by annealing. Instead, the dislocations accumulate, interact with one another, and serve as pinning points or obstacles that significantly impede motion. This leads to an increase in the yield strength of the material and a subsequent decrease in ductility (Parker and Basset, 1964; Hue and Bratt, 1958).

To the best of our knowledge, there is no research in the literature on the determination of parameters of power-law hardening material at different tensile test conditions. In this research, two distinct conditions are considered: without heat treatment and with heat treatment to show if there is any variation of the values of $n$ and $\alpha$ of $\mathrm{Cu}$ material. In Kowser and Mahiuddin (2012) and (2013) the techniques are also presented for $\mathrm{Cu}$ material.

Tensile curves with $\alpha=1$ corresponding to a usual engineering definition of yield are shown in Fig. 1 for several values of the stress hardening exponent, $n$ (Hutchinson, 1967).

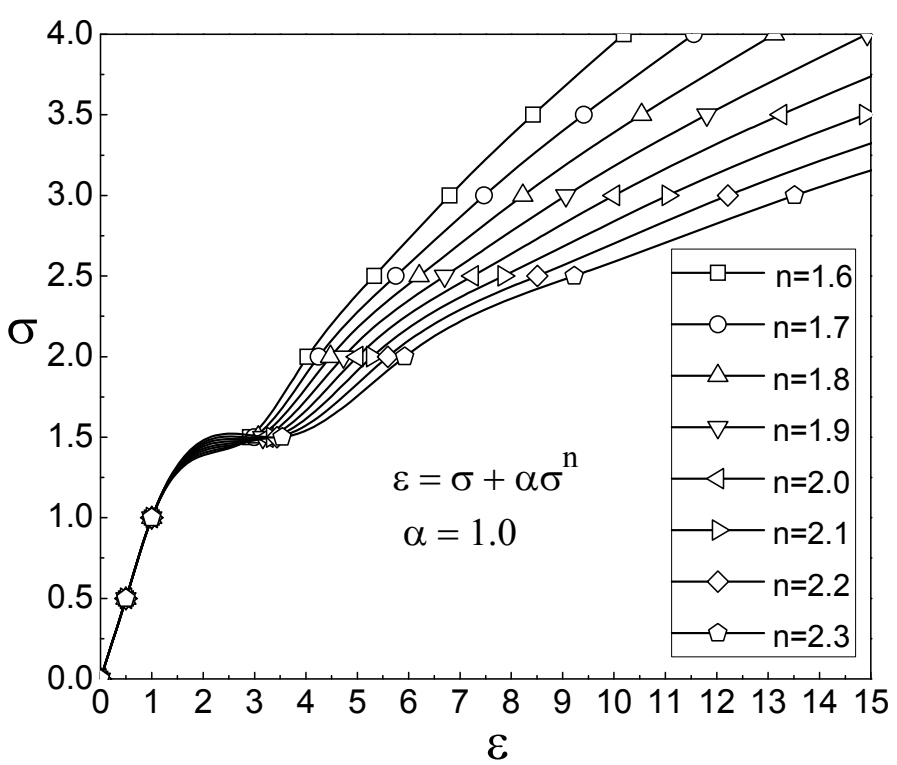

Fig.1. Stress-strain diagram for the variation of $n$ at constant $\alpha$. 
Tensile curves with $n=2.2$ corresponding to a usual engineering definition of yield are shown in Fig. 2 for several values of the power-law hardening constant $\alpha$.

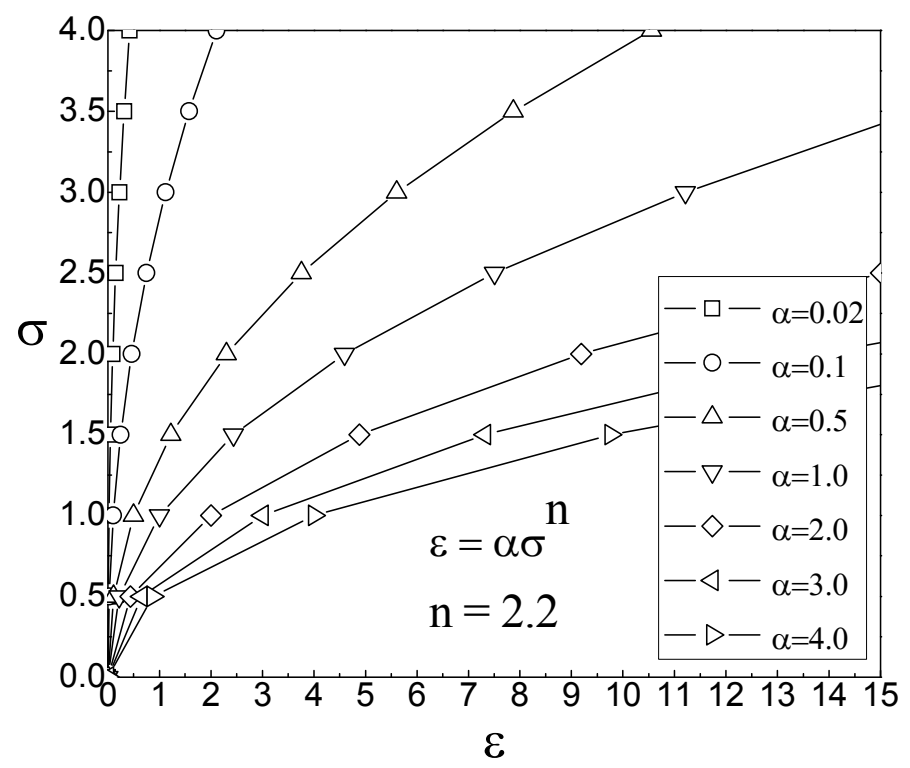

Fig.2. Stress-strain diagram for the variation of $\alpha$ at constant $n$.

The level of $n$ is particularly significant in stretch forming because it indicates the ability of a metal to distribute the strain over a wide range.

Physical \& Mechanical Properties: The physical and mechanical properties of the material are given in Tab.1a and Tab.1b, respectively.

Table 1a. Physical properties of copper [25]

\begin{tabular}{l|l}
\hline Parameter & \multicolumn{1}{|c}{ Copper } \\
\hline Melting Temperature & $1084.62^{\circ} \mathrm{C}$ \\
Density & $8.96 \mathrm{gm} / \mathrm{cm}^{3} @ 20^{\circ} \mathrm{C}$ \\
Specific Gravity of & 8.96 \\
Coefficient & $16.5 \mu \mathrm{m} \cdot \mathrm{m}^{-1} \cdot \mathrm{K}^{-1}\left(25^{\circ} \mathrm{C}\right)$ \\
Thermal Expansion & \\
Thermal Conductivity & $401 \mathrm{~W} \cdot \mathrm{m}^{-1} \cdot \mathrm{K}^{-1}$ \\
Electrical Resistivity & $16.78 \mathrm{n} \Omega \cdot \mathrm{m}^{\circ}\left(20^{\circ} \mathrm{C}\right)$ \\
(Annealed) & $24.440 \mathrm{~J} \cdot \mathrm{mol}^{-1} \cdot \mathrm{K}^{-1}$ \\
Specific Heat & \\
Annealing & $371{ }^{\circ} \mathrm{C}-649^{\circ} \mathrm{C}$ \\
Temperature & \multicolumn{2}{|c}{} \\
\hline
\end{tabular}


Table 1b. Mechanical properties copper [25]

\begin{tabular}{l|l}
\hline Parameter & Copper \\
\hline Young's & $110-128 \mathrm{GPa}$ \\
modulus & $48 \mathrm{GPa}$ \\
Shear modulus & $240 \mathrm{MPa}$ \\
Tensile strength & $20-60 \%$ \\
Elongation & $75 \mathrm{MPa}$ \\
Fatigue Strength & $70 \mathrm{MPa}$ \\
Yield strength & 7 \\
\hline
\end{tabular}

\section{Experimental methods}

The mechanical properties of a material are directly related to the response of the material when it is subjected to mechanical stresses. Since characteristic phenomena or behavior occur at discrete engineering stress and strain levels, the basic mechanical properties of a material are found by determining the stresses and corresponding strains for various critical occurrences. A wealth of information about mechanical behavior of a material can be determined by conducting a simple tensile test in which a cylindrical specimen of a uniform cross-section is pulled until it ruptures or fractures into separate pieces. The original cross sectional area and gauge length are measured prior to conducting the test and the applied load and gage displacement are continuously measured throughout the test. Based on the initial geometry of the sample, the engineering stress-strain behavior (stress-strain curve) can be easily generated from which numerous mechanical properties, such as yield strength and elastic modulus, can be determined. A universal testing machine shown in Fig.3 is utilized to apply the load in a continuously increasing (ramp) manner according to ASTM specifications.

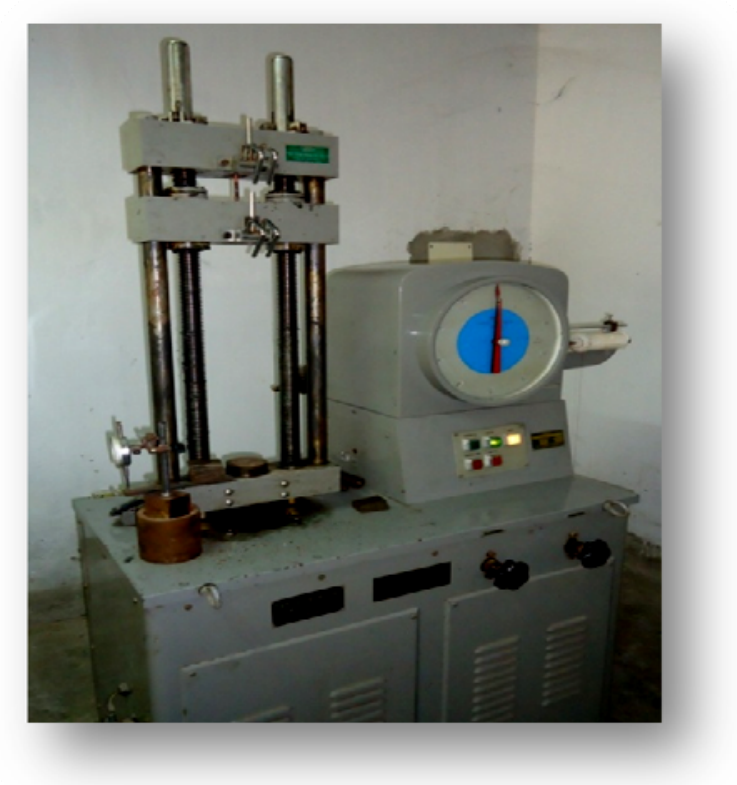

Fig.3. Universal Testing Machine. 
Tensile test specimens of $\mathrm{Cu}$ are presented in Fig.4 and Fig.5 respectively. Each specimen is of a specific shape and dimensions that prepared in accordance with ASTM (American Society for Testing and Materials) specifications for standardization. During tests, deformation is confined to the narrow center region which has a uniform cross section along its length.

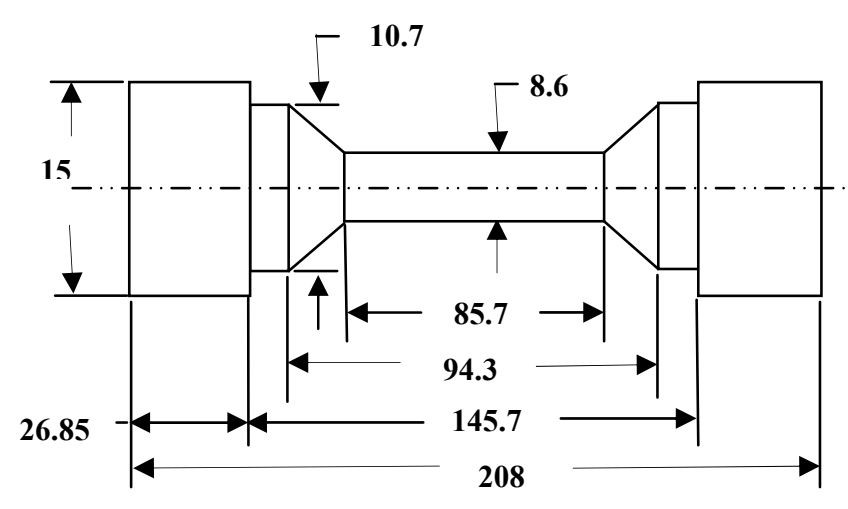

Fig.4. ASTM standard tensile test specimen.

Dimensions of tensile test specimens are given in Tab.2.

Table 2. Dimensions of tensile test specimens.

\begin{tabular}{c|c|c|c}
\hline Mat. & $\begin{array}{c}\text { Specimen } \\
\text { No }\end{array}$ & $\begin{array}{c}\text { Diameter } \\
(\mathbf{m m})\end{array}$ & $\begin{array}{c}\text { Gauge } \\
\text { Length (mm) }\end{array}$ \\
\hline & 1 & 6.80 & 69.00 \\
& 2 & 6.85 & 74.30 \\
$\overline{\grave{\Xi}}$ & 3 & 7.11 & 69.00 \\
$\bar{\Xi}$ & 4 & 6.95 & 74.70 \\
& 5 & 7.00 & 74.30 \\
& 6 & 6.90 & 74.80 \\
\hline
\end{tabular}

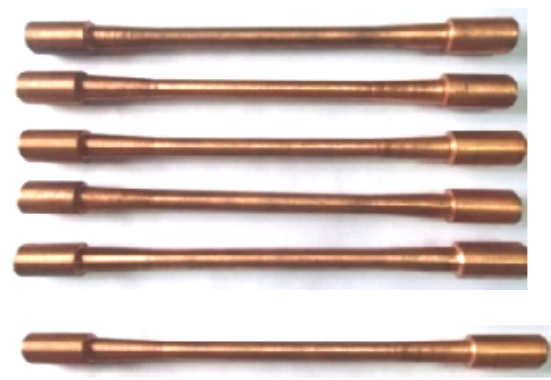

Fig.5. Tensile test specimen of $\mathrm{Cu}$. 


\section{Experimentation}

Experiments were carried out in two different conditions, without heat treatment and with heat treatment.

\subsection{Heat treatment}

Heat treatment is the controlled heating and cooling of metals to alter their physical and mechanical properties without changing the product shape.

Transformation hardening mechanisms resulting from quenching at high temperatures induce internal changes producing harder, stronger phases. Tempering such structures improves toughness and reduces hardness

The heat treatment process was carried out in an electric furnace. Processing of specimens and recorded temperatures are shown in Fig.6 and Fig.7.

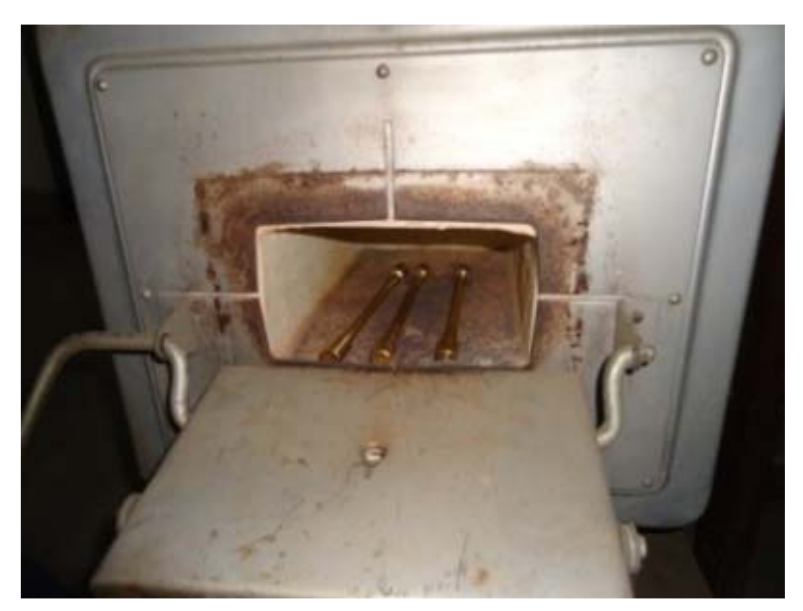

Fig.6. Heat treatment process.

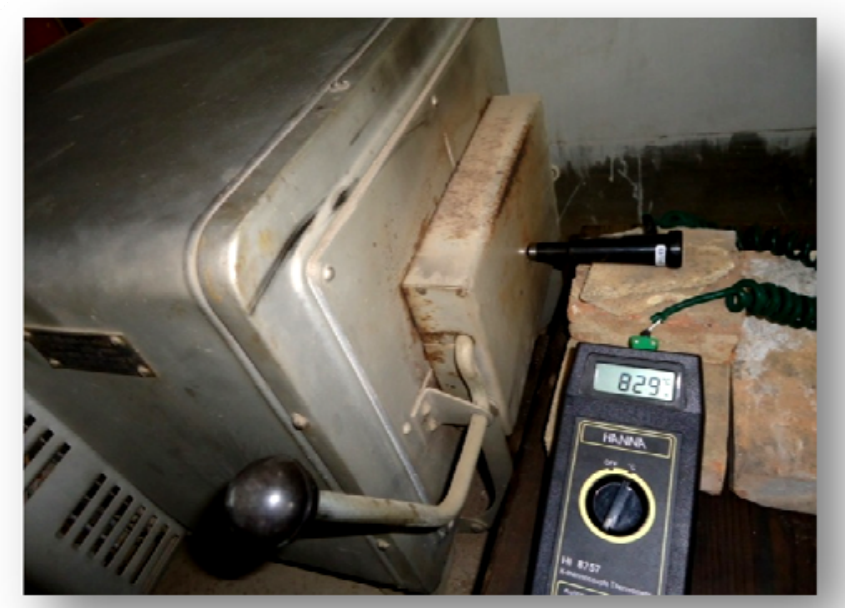

Fig.7. Heat treatment process showing recorded temperature. 
$\mathrm{Cu}$ specimens were heated to $829^{\circ} \mathrm{C}$ and $715^{\circ} \mathrm{C}$ respectively for 30 minutes and cooled to room temperature slowly. Time-temperature curve of heat treatment process is shown in Fig.8.

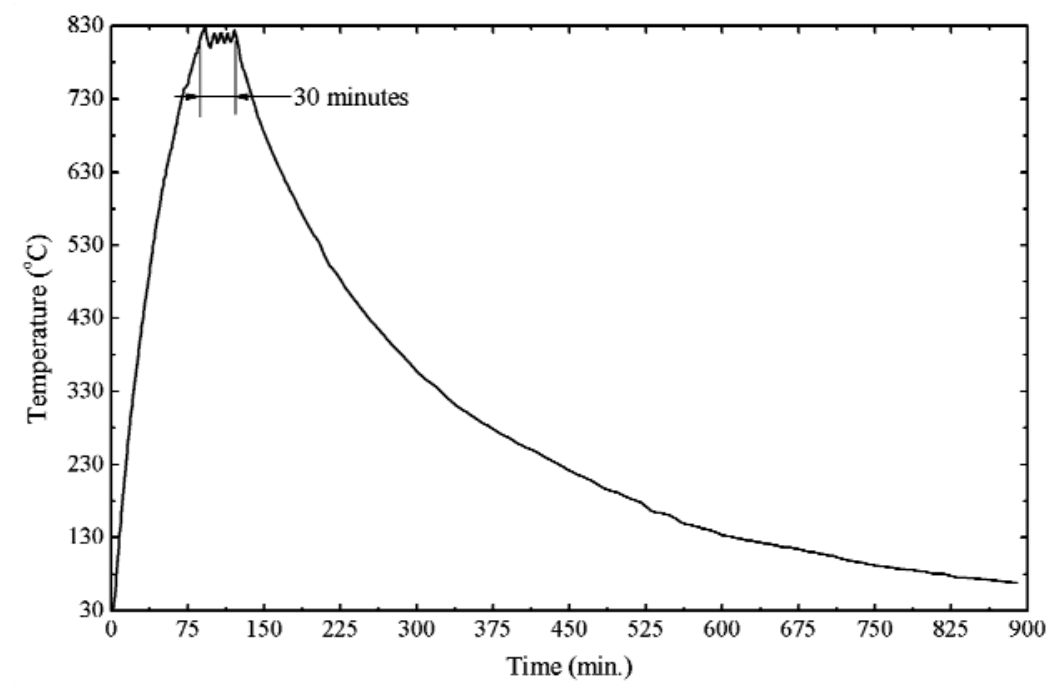

Fig.8. Time - Temperature curve of heat treatment process.

\section{Test results}

Engineering and true stress- strain curves for the tensile tests before heat treatment and after heat treatment are shown in Fig.9 to Fig.13.

The combined effect of engineering and true stress-strain curve before and after heat treatment for $\mathrm{Cu}$ is shown in Fig.9 and Fig.10.

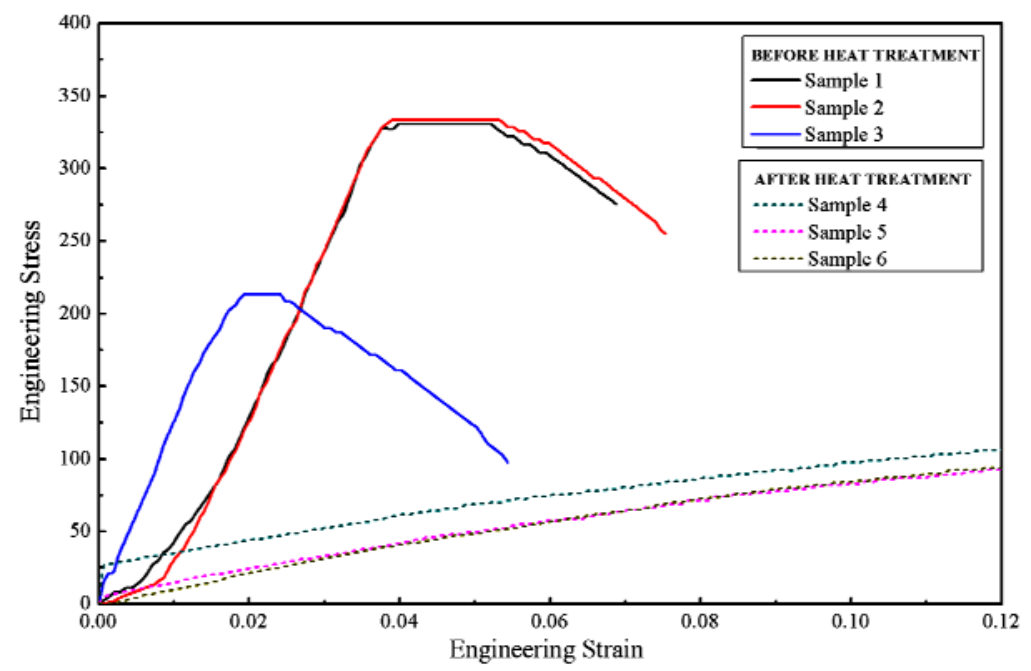

Fig.9. Engineering stress - strain diagram for $\mathrm{Cu}$ before and after heat treatment. 


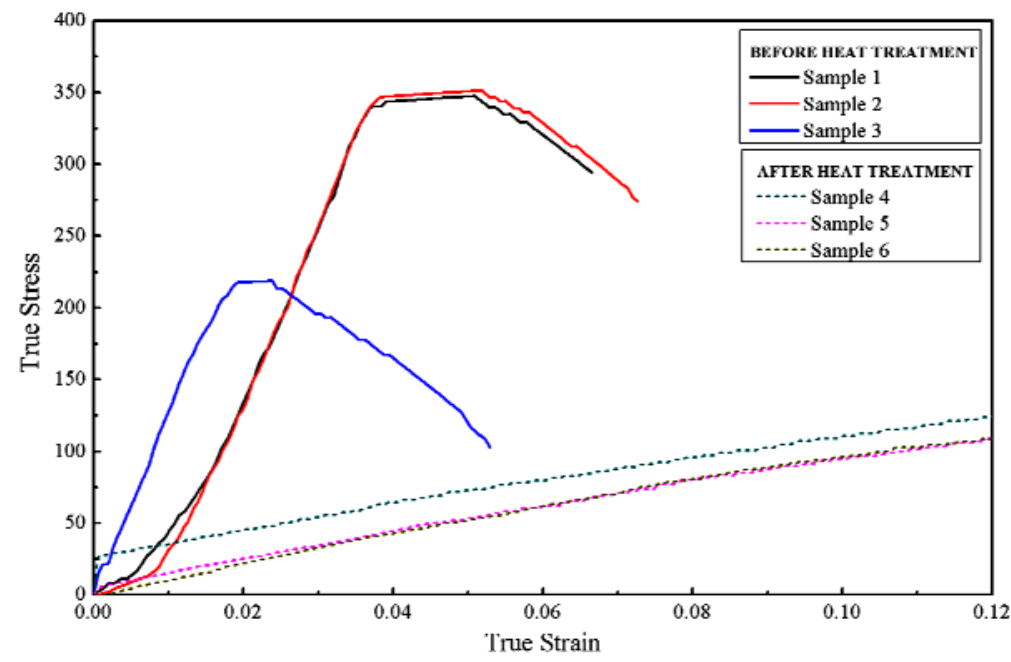

Fig.10. Combined true stress - strain diagram.

\section{Determination of $\alpha$ and $n$}

Hollomon's equation is a power law relationship between the stress and the amount of plastic strain

$$
\varepsilon=\alpha \sigma^{n}
$$

The constant $\alpha$ is structure dependent and is influenced by processing while $n$ is a material property. Applying the power law at two levels of stress, $\varepsilon_{1}$ and $\varepsilon_{2}$ can be given as

$$
\begin{aligned}
& \varepsilon_{1}=\alpha \sigma_{1}{ }^{n}, \\
& \varepsilon_{2}=\alpha \sigma_{2}{ }^{n}
\end{aligned}
$$

Taking the ratios equation yields

$$
\frac{\varepsilon_{1}}{\varepsilon_{2}}=\left(\frac{\sigma_{1}}{\sigma_{2}}\right)^{n} .
$$

Finally, taking the natural logs of both sides; the stress hardening exponent can be described by

$$
n=\frac{\ln \left(\frac{\varepsilon_{1}}{\varepsilon_{2}}\right)}{\ln \left(\frac{\sigma_{1}}{\sigma_{2}}\right)} .
$$

Equation (5.5) can be evaluated from the slope of a $\log (\sigma)-\log (\varepsilon)$ plot. The true stress-strain relation plots as a straight line on log-log coordinates as shown in Fig.11. The stress hardening exponent $n$ is the slope of the line. The value of $n$ can be determined by Eq.(5.5). 


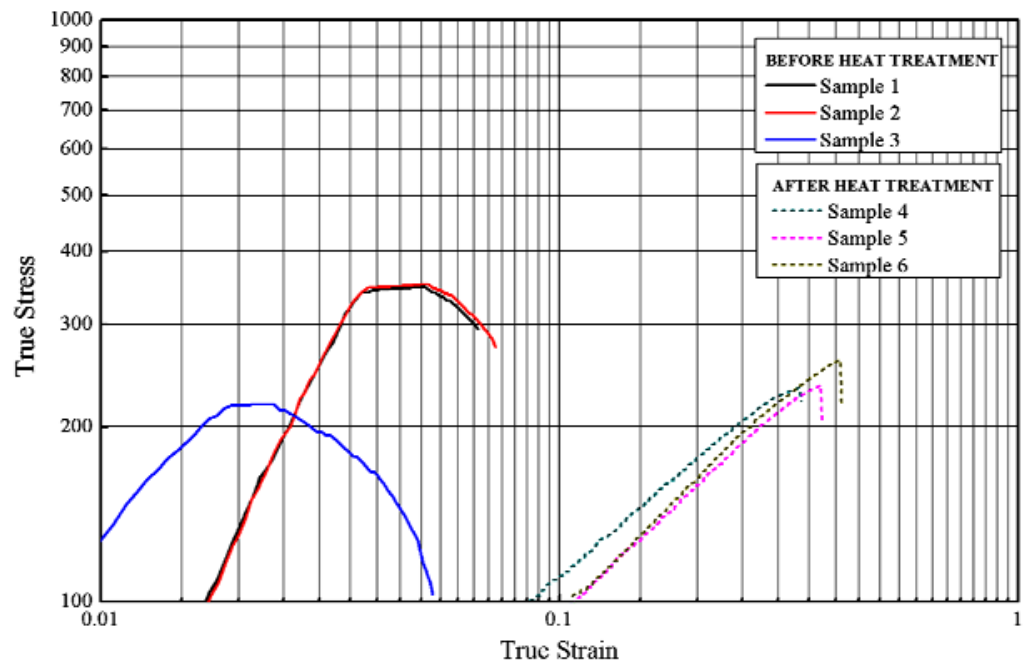

Fig.11. True stress - strain diagram on logarithmic scale.

The power-law hardening constant, $\alpha$ can be found by extrapolating to $\varepsilon=1.0$, where $\alpha$ is the value of $\sigma$ when $\varepsilon=1.0$.

Experiments were carried out in two distinct conditions. One was in ambient condition and another was heat treated condition. Numerical results are presented in a tabular form in Tab.3, for $\mathrm{Cu}$ material.

Table 3. Experimental value of $n$ and $\alpha$.

\begin{tabular}{|c|c|c|c|c|c|}
\hline Mat. & $\begin{array}{c}\text { Specimen } \\
\text { No }\end{array}$ & $\begin{array}{l}\text { Value } \\
\text { of } n\end{array}$ & $\begin{array}{l}\text { Value } \\
\text { of } \alpha\end{array}$ & $\begin{array}{l}\text { Avg. } \\
\text { of } n\end{array}$ & $\begin{array}{c}\text { Avg. of } \\
\alpha\end{array}$ \\
\hline \multirow{6}{*}{$\frac{\grave{d}}{\grave{a}}$} & 1 & 1.51 & 5.30 & \multirow{3}{*}{1.52} & \multirow{3}{*}{4.54} \\
\hline & 2 & 1.49 & 4.21 & & \\
\hline & 3 & 1.56 & 4.10 & & \\
\hline & 4 & 1.48 & 4.75 & \multirow{3}{*}{1.38} & \multirow{3}{*}{5.03} \\
\hline & 5 & 1.35 & 5.44 & & \\
\hline & 6 & 1.30 & 4.91 & & \\
\hline
\end{tabular}

From various sources including Hosford (2005) a comparison of the theoretical and experimental value of $n$ and $\alpha$ was made and presented in Tab.4 and Tab.5, respectively.

Table 4. Comparison of theoretical and experimental value of $n$ before heat treatment.

\begin{tabular}{c|c|c|c}
\hline Mat. & $\begin{array}{c}\text { Theory[1] } \\
\boldsymbol{n}\end{array}$ & $\begin{array}{c}\text { Experimental } \\
\boldsymbol{n}\end{array}$ & \% Error \\
\hline Copper & 2.0 & 1.52 & 24 \\
\hline
\end{tabular}


Table 5. Comparison of theoretical and experimental value of $\alpha$ before heat treatment.

\begin{tabular}{c|c|c|c}
\hline Mat. & $\begin{array}{c}\text { Theory[1] } \\
\alpha\end{array}$ & $\begin{array}{c}\text { Experimental } \\
\alpha\end{array}$ & \% Error \\
\hline Copper & 4.50 & 4.54 & 0.88 \\
\hline
\end{tabular}

The comparison of theoretical results with experimentally obtained results at ambient conditions for $\mathrm{Cu}$ is also shown in Fig.12, where the best matched curve for one specimen is shown.

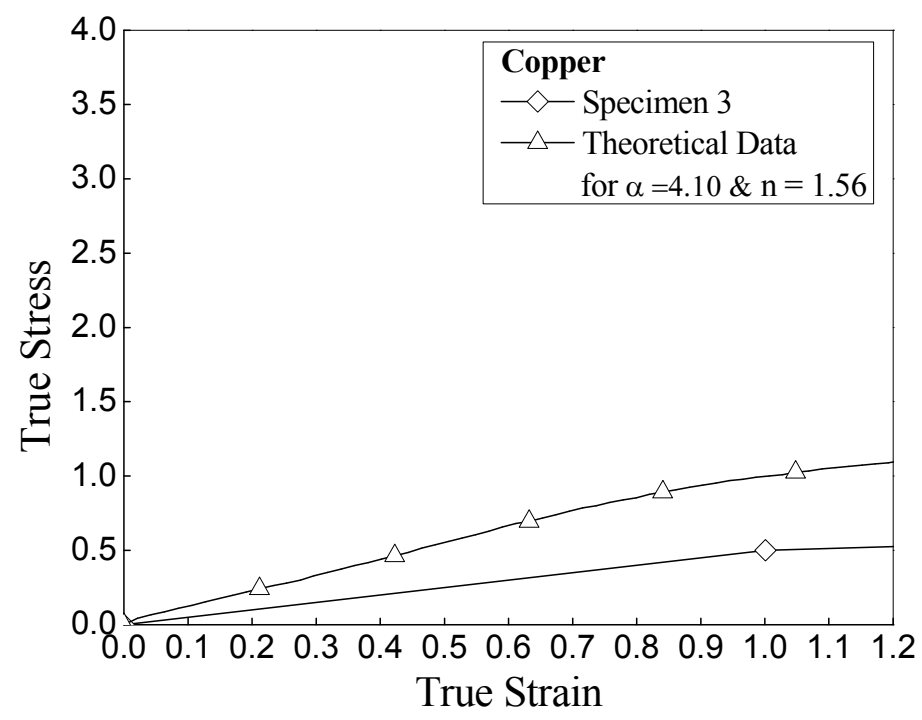

Fig.12. Comparison of theoretical and experimental results at ambient temperature.

The comparison of theoretical results with experimentally obtained results after heat treatment of $\mathrm{Cu}$ is shown in the Fig.13. Where the best matched curve for one specimen is shown for the simplicity of results.

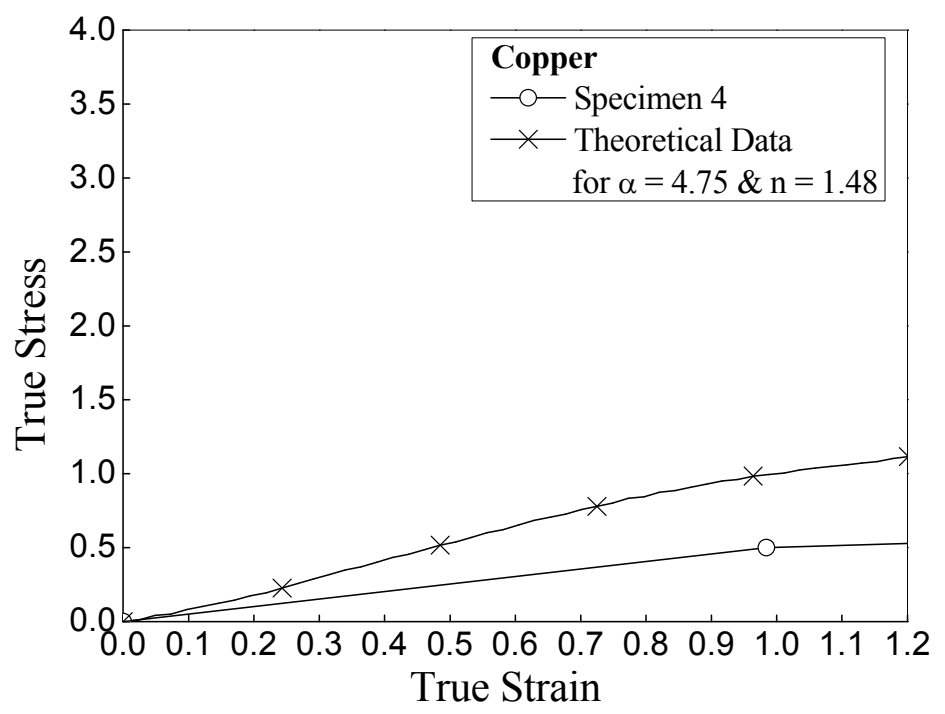

Fig.13. Comparison of theoretical and experimental results at ambient temperature. 


\section{Conclusion}

From the tensile test data of ASTM standard specimens of $\mathrm{Cu}$, a simple technique is presented to determine the power-law hardening parameters. From the tensile test data for two distinct conditions, i.e., without heat treatment and with heat treatment, the values of $n$ and $\alpha$ are obtained for various specimens of $\mathrm{Cu}$ as a power law hardening material. Without heat treatment the obtained experimental results are compared with available theoretical results. There are significant reductions of the values of $n$ for both the materials. There are remarkable changes in strain for the same stress at different $n$ due to the non- linear behavior of the materials. The above results suggest that the value of $n$ should be determined after heat treatment of $\mathrm{Cu}$ materials for their applications in engineering fields.

\section{Nomenclature}

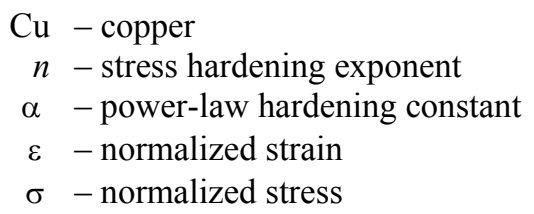

\section{References}

Available:http://www.webelements.com/copper/ physics. htm

Batdorf S.B. and Budiansky B. (1949): A mathematical theory of plasticity based on the concept of slip. - NACA TN 1871.

Denke P.H. (1956): The matrix solution of certain nonlinear problems in structural analysis. - Journal of Aerospace and Sciences, vol.23, No.3, pp.231-236.

Hodge P.G. (1959): Plastic Analysis of Structures. - New York: McGraw Hill.

Hosford F. William (2005): Mechanical Behavior of Materials. - USA: University of Michigan.

Hue L.W. and Bratt J.F. (1958): Effect of tensile plastic deformation on the yield condition. - Journal of Applied Mechanics, vol.25, pp.111.

Hutchinson J.W. (1967): Singular behavior at the end of a tensile crack in a hardening material. - Journal of the Mechanical and Physics of Solids, vol.16, pp.13-31.

Isakson G., Armen H. Jr. and Pifko A. (1967): Discrete-element methods for the plastic analysis of structures. National Aeronautics and Space Administration, Washington D.C..

Kowser M.A. and Mahiuddin M. (2012): Technique for determining the constant parameters of power-law hardening material by tensile test. - Proceedings of 6 IMEC \& 14 APM, Dhaka, Bangladesh.

Kowser M.A. and Mahiuddin M. (2013): Technique for determining the constant parameters of Cu as a power-law hardening material at different conditions. - Proceedings of ICERIE, SUST, Sylhet, Bangladesh, Jan. 11-13.

Kucharski S. and Mróz Z. (2007): Identification of yield stress and plastic hardening parameters from a spherical indentation test. - International Journal of Mechanical Sciences, vol.49, pp.1238-1250.

Lin X. and Tzuchiang W. (1992): The interfacial crack between two dissimilar elastic-plastic materials. - Acta Mechanica Sinica, vol.8, No.2.

Lin Xia and Wang T. (1993): Singular behavior near the tip of a sharp V-notch in a power law hardening material. International Journal of Fracture, 59:83-93.

Marin J. and Hue L.W. (1953): On the validity of assumptions made in theories of plastic flow for metals. - Transaction ASME, vol.75, No.6, pp.1181. 
Naghdi P.M. (1960): Stress-strain relations in plasticity and thermo-plasticity. - Proceedings of 2nd Symposium on Naval Structural Mechanics, pp.121.

Neal B.G. (1950): Plastic collapse and shakedown theorems for structures of strain-hardening material. - Journal of Aerospace and Sciences, vol.17, No.5, pp.297.

Parker J. and Basset M.B. (1964): Plastic stress-strain relationships-some experiments to derive a subsequent yield surface. - Journal of Applied Mechanics, vol.31, pp.676.

Perrone N. and Hodge P.R. Jr. (1957): Applications of a consistent theory for strain-hardening plastic solids. - PIBAL Report 403.

Prager W. (1956): A new method of analyzing stress and strain in work hardening plastic solids. - Journal of Applied Mechanics, vol.23, P.493.

Prager W. (1955): The theory of plasticity: a survey of recent achievements. - Proceedings of Institution of Mechanical Engineers, vol.169, pp.41.

Ramberg W. and Osgood W.R. (1960): Description of stress-strain curves by three parameters. - NACA TN 902.

Rivello R.M. (1960): Ramberg-Osgood and hill parameters of aircraft structural materials at elevated temperatures. University of Maryland, Aerospace Engineering Department, Rep. 60-1.

Sanders Jr. J.L. (1954): Plastic stress-strain relations based on linear loading functions. - Proceedings of 2 nd U.S. National Congress Appl., pp.455.

Symonds P.S. and Prager W. (1950): Elastic-plastic analysis of structures subjected to loads varying arbitrarily between prescribed limits. - Journal of Applied Mechanics, vol.17, No.3, pp.315.

Xia L. and Tzuchiang W. (1994): Higher-order analysis of near-tip fields around an interfacial crack between two dissimilar power law hardening materials. - Acta Mechanica Sinica, vol.10, No.1.

Received: October 18, 2013

Revised: October 10, 2014 